\title{
LETTERS
}

\section{Secure care: a question of capacity, autonomy and the best interests of the child}

We agree with Pilarinos and colleagues that secure care is not the solution to the overdose crisis. ${ }^{1}$ We further agree that evidence-based addiction treatment for youth is largely nonexistent and urgently needed.

However, we concur with Warshawski and colleagues that the references used in the commentary by Pilarinos and colleagues do not support the conclusion that secure care is ineffective. ${ }^{2}$ Further, the references used in the authors' response to comments, if anything, support the opposite conclusions to those reached in the response, which states, "Coercive interventions to treat addiction have been found to be inadequate in reducing negative substance use outcomes while increasing mental duress and risk of overdose." ${ }^{3}$

Contrast that with what the references cited in that sentence said. From Pasareanu and colleagues: "Voluntary treatment for SUD [substance use disorder] generally yielded better outcomes; nevertheless, we also found improved outcomes for CA [compulsorily admitted] patients. It is important to keep in mind that in reality, the alternative to CA treatment is no treatment at all and instead a continuation of life-threatening drug use behaviours. Our observed outcomes for CA patients support the continuation of CA treatment." 4

Also from Pasareanu and colleagues: "In-patient treatment reduces mental distress for both CA and VA [voluntarily admitted] patients. The time after discharge seems critical especially for CA patients regarding active substance use and severe mental distress. A greater focus on continuing care initiatives to assist the CA patients after discharge is needed to maintain the reduction in mental distress during treatment." 5

From Rafful and colleagues: "Overall, IDT [involuntary drug treatment], as other type of forced abstinence, reduces drug tolerance, putting PWID [people who inject drugs] at risk of non-fatal overdose. ... This study highlights the life-threatening risks
PWID experience in relation to IDT." ${ }^{6} \mathrm{How}$ ever, this study involved people with opioid use disorder, for whom the standard of care is medication-assisted treatment. How can one conclude that involuntary treatment does not work when evidencebased treatment was not received? A better conclusion would be that treatment for opioid use disorder without medicationassisted treatment increases the risk of nonfatal overdose.

Given the lack of evidence-based treatment for minors, it is not surprising that there is a paucity of research comparing outcomes for minors who have received treatment voluntarily and involuntarily. And given that relapse is common in youth who have received treatment voluntarily, it is problematic to use relapse as the indication that involuntary treatment is not effective.

The issue of involuntary treatment concerns the capacity of youth to refuse treatment. A major barrier to treatment of youth with substance use disorder and concurrent mental health conditions is their inability to understand that their

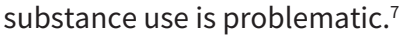

Further, youth with substance use disorder may be involved in criminal activity to support their addiction. If they are not caught upstream in the mental health net, they will be caught downstream in the criminal justice net, the child welfare net, hospital emergency departments and the morgue. ${ }^{8}$

The adolescent brain continues to develop until the mid-20s. The last part to develop is the prefrontal cortex, responsible for executive functions such as insight, decision-making, judgment, planning and impulse control. Incomplete development of the prefrontal cortex can affect capacity to make treatment decisions.

Further, addiction impairs autonomy. Autonomy is typically defined as selfdetermination free from both controlling interferences by others and personal limitations preventing meaningful choice (e.g., inadequate understanding or faulty reasoning). "If we know anything about addiction at all, it is that it impairs autonomy in some way. Loss of control - in some manner and to some degree - over drug-seeking and consuming behavior is a defining feature of addiction, as it is popularly and scientifically conceived." Some of the criteria for substance use disorder in the Diagnostic and Statistical Manual of Mental Disorders, Fifth Edition, reflect a lack of choice. If substance use is no longer a choice, there is not autonomy with respect to use.

Physicians receive little education about addiction and less about assessing capacity. Minors struggling with addiction, whose main impairment is an ability to say no to substance use (or yes to treatment) are not being assessed to determine if they actually have capacity to refuse treatment.

Canada is a party to the UN Convention on the Rights of the Child (UNCRC).

Article 3 provides that in all actions concerning children, including the drafting of our laws, the best interests of the child must be a primary consideration.

Article 24 provides that no child be deprived of the right of access to health care services, including those directed to the rehabilitation of health.

Article 33 provides that children have the right to be protected from the use of illegal drugs and from being used in the drug trade.

Read as a whole, the sensible interpretation of the UNCRC is that addicted minors, in their best interests, should receive treatment, regardless of their refusal, so they can recover, instead of being harmed by criminalization or untreated and progressive addiction. This conclusion is supported in a 2009 report ${ }^{10}$ from a conference held at the University of Toronto, which concluded the following:

- putting the best interest of the child first would require substantial changes in current models of formal health care; - strategies are required to keep young people out of the criminal justice system;

- codes of conduct by the colleges of health professionals on the best interests of the child are required.

Legislation similar to the Secure Care Act currently being considered in British Columbia was at issue in a 2017 inquiry 
into the overdose death of a 17-year-old in Alberta. ${ }^{11}$ Judge Robertson referred to the duty of the state to protect vulnerable youth and concluded that confinement for stabilization purposes is insufficient; confinement should be for purposes of treatment. Judge Robertson recommended that the available length of continuous secure treatment should be no less than 120 days, but 180 days would be better. Confinement to protect should not be confused with confinement to punish.

A 2018 investigative report of the Office of The Child and Youth Advocate Alberta into the deaths of 12 youth aged 15-19 from overdose referred to Article 33 of the UNCRC in calling for more protective health laws for youth. ${ }^{12}$

A 2018 report of the Manitoba Advocate for Children and Youth called for more treatment (including involuntary) for youth to reduce the harms of sexual exploitation and untreated addiction. ${ }^{13}$ It concludes, "[e]merging research on involuntary treatment suggests safe and secure treatment ought to be part of the continuum of options for children and youth struggling with addictions. This research also reveals that 'secure facilities' do not need to be institutions. They can be secured via adequate staffing, geographic locations, and be holistic and culturally-based homelike settings."
Angie L. Hamilton LLB

Executive director, Families for Addiction

Recovery, Scarborough, Ont.

Daphne G. Jarvis LLB

Lawyer, partner, Borden Ladner Gervais

LLP, Toronto, Ont.

\section{Barbara E.L. Watts MD}

Emergency physician, Headwaters Health

Care Centre, Orangeville, Ont.

— Cite as: CMAJ 2020 February 3;192:E121-2. doi: $10.1503 / \mathrm{cmaj} .73252$

\section{References}

1. Pilarinos $A$, Kendall $P$, Fast $D$, et al. Secure care: more harm than good. CMAJ 2018;190:E1219-20.

2. Warshawski T, Charles G, Vo D, et al. Secure care can help youth reduce imminent risk of serious harm and prevent unnecessary death [letter]. CMAJ 2019;191:E197-8.

3. DeBeck K, Kendall P, Fast D, et al. The authors respond to comments on the use of secure care in youth [letter]. CMAJ 2019;191:E199-200.

4. Pasareanu AR, Vederhus J-K, Opsal A, et al. Improved drug-use patterns at 6 months postdischarge from inpatient substance use disorder treatment: results from compulsorily and voluntarily admitted patients. BMC Health Serv Res 2016;16:291.

5. Pasareanu AR, Vederhus J-K, Opsal A, et al. Mental distress following inpatient substance use treatment, modified by substance use; comparing voluntary and compulsory admissions. BMC Health Serv Res 2017;17:5.

6. Rafful C, Orozco R, Rangel G, et al. Increased non-fatal overdose risk associated with involuntary drug treatment in a longitudinal study with people who inject drugs. Addiction 2018;113: 1056-63.
7. Watson GK, Carter C, Manion I. Pathways to care for youth with concurrent mental health and substance use disorders. Ottawa: Ontario Center of Excellence for Child and Youth Mental Health; 2014.

8. Schneider RD. The mentally ill: how they became enmeshed in the criminal justice system and how we might get them out. Ottawa: Department of Justice Canada; 2015.

9. Levy N. Addiction, autonomy, and informed consent: on and off the garden path. J Med Philos 2016;41:56-73.

10. Canadian Coalition for the Rights of Children. Best interests of the child: meaning and application in Canada [report]. Toronto: The Faculty of Law, University of Toronto; 2009 June 1. Available: www.law. utoronto.ca/documents/conferences/Bestlnterests Child-Report_en.pdf (accessed 2019 July 18).

11. Public Fatality Inquiry Report to the Minister of Justice and Solicitor General, The Honourable Judge Lloyd W Robertson into the death of MHC, 17 of Calgary, Alberta [report]. Edmonton: Alberta Government; 2017 Nov. 6. Available: open.alberta.ca/ dataset/52541654-7b38-4a30-8723-9f301fd4d11a/ resource/ea5ae196-3833-480c-9c9a-ec576d41fbd1/ download/m.c.-report-to-jsg.01419redacted.pdf (accessed 2018 Jan. 2).

12. Graff D. Into focus: calling attention to youth opioid use in Alberta. Edmonton: The Office of the Child and Youth Advocate; 2018 June 1. Available: www. ocya.alberta.ca/wp-content/uploads/2014/08/ InvRev_IntoFocus-OpioidRpt_2018June-1.pdf (accessed 2018 July 15).

13. In need of protection: Angel's story. Winnipeg: Manitoba Advocate for Children and Youth; 2018;98. Available: https://manitobaadvocate. ca/wp-content/uploads/In-Need-Of-Protection -Angels-Story-Dec-2018.pdf (accessed 2019 July 2).

Competing interests: Daphne Jarvis was retained by Families for Addiction Recovery to provide legal advice on the issues addressed in this response. No other competing interests were declared. 